\title{
Resources Management and Rent Theory in Mining Industry
}

\author{
Marius Bulearca ${ }^{1}$, Catalin Popescu ${ }^{2}$, Mihai-Sabin Muscalu $^{1}$ and Constantin Ghiga ${ }^{3}$ \\ ${ }^{1}$ Center for Industry and Services Economics, Bucharest, Romanian Academy, Bucharest, Romania \\ ${ }^{2}$ Oil and Gas University, Ploiesti, Romania \\ ${ }^{3}$ University of Bucharest, Bucharest, Romania
}

\begin{abstract}
Highlighting both the problems of composing and acquiring mineral rent, and the procedures and forms in which the rent is reflected in the price of mining products and energy resources are basic premises to emerge specific methodological elements of economic management of mineral resources. As our researches revealed, contractual duties represent one of these elements. Hence, the problem of new approaching in mining rents is to select policies for the contractual duty to provide sufficient incentives for foreign companies engaged in exploration and extraction of resources, by obtaining the broadest possible part of that resource rent.
\end{abstract}

Presentation and evaluation of a variety of different contractual taxation systems usually used in developing countries depends on the variety of different economic and geological conditions, where of particular interest are the geological conditions that allow a low probability to discover new resources. As a result, the hypothesis was that some regularity should appear in effectiveness of the schemes themselves although current rates that are fixed in any given schema are designed to be sensitive to basic conditions.

To have a successful economic management of natural resources, at the end of this paper different types and sources of inefficiency of resource management along with the market and Government failures in this respect are revealed.

Keywords: Exhaustibility, property rights regime, contractual duties, market and Government failures.

\section{Introduction}

Economic analysis of extractive industry is fundamentally different from the analysis of agriculture, manufacturing and services. The main reason is that the mineral resources are exhaustible resources. In other words, in mining industry an initial stock of reserves will exhaust in time. If we start from the premise that the owner of a resource, like any other owner, is seeking for maximum gain, then it must consider specific factors, unique in the mining industry.

In economic analysis in general, and especially that related to natural resources market, has been prevalent until now, the concept of their scarce character, in this

Copyright (C) 2012 Marius Bulearca, Catalin Popescu, Mihai-Sabin Muscalu and Constantin Ghiga. This is an open access article distributed under the Creative Commons Attribution License unported 3.0, which permits unrestricted use, distribution, and reproduction in any medium, provided that original work is properly cited. Contact author: Marius Bulearca E-mail: mariusbulearca@yahoo.com 
respect, much of the methodological concepts being closely related to resources allocation problems at micro and macro-economic level.

Based on these considerations, it should be noted that in the economic literature, there has been often accredited to the idea of resource reserves depletion, due to the extent of economic and demographic development. But it must be taken into account that natural resources are not homogeneous in nature.

Therefore, the problem of modeling mining rents, put in simple terms, is to select policies for the contractual duty to provide sufficient incentives for foreign companies engaged in exploration and extraction of resources, by obtaining the broadest possible part of that resource rent. Although this issue has some elements of the problem of attracting foreign investors, it is different in many respects.

It has been also noticed that, in terms of economic management of natural resources, the social importance of analysis of resources misuse is facilitated by the study of two related concepts.

The first is the social opportunity cost of resource use. This cost is about the optimum level at which resources can be used. The second concept is that of the total economic value. This value expresses the largest parts of the conservation value of natural resources in a tolerable way. The analysis of both concepts is also extended at the end of this paper.

\section{A New Approach of Rent Theory in Mining Industry}

In a perfect competition between owners of land with deposits of mineral resources, exhaustibility annuity/rent is the absolute rent ceiling [14]. Its existence does not exclude the emergence of monopoly rent, if conditions allow competition, the two being always limited by the price of the substitute. However, differences between interest rates received by landowners may lead to a greater supply of land with deposits of mineral resources, leased at a price lower than set by theory [19].

The main problem that arises consist in the results that are obtained by exploiting these deposits, because in reality, time to exhaustion $\mathrm{T}_{0}$ is not known with certainty. So from undisputable economic reasons, exhaustibility annuity growths in relation to interest rate " $i$ ", but its level at time " $t$ " can not be rigorously determined.

In this respect, the essential problem in dealing with rent in the mining industry is to determine with some certainty the operating range up to exhaustion of a reservoir, because, economically, exhaustibility annuity/rent is to increase interest in certain fields with low useful elements and/or difficult conditions of extraction, but its level for a certain time horizon can not be practically determined.

For example, the debates which took place after the first OPEC oil crisis [5, 25], have proposed a new price formula called "Taïb", whereby the real price of oil would grow at the same pace with economic growth. But after the confrontation of interests and opinions concluded that, if one accepts a certain horizon of depletion of oil reserves (it was estimated that oil reserves at costs less than the substitute for coal will reach tens years of consumption) by applying this formula the oil price should be below the baseline [26].

Returning to the question of acquiring rents we must distinguish between rents that are obtained as a result of differences in quality of deposits, and those which are created by the "market" and which are the object of an open fight for acquiring them. In the first case can be found, for example, absolute rents created and acquired by tax measures imposed by the State as the sole owner of mineral resources (e.g., oil-producing states decide to create an additional duty on crude oil sales by $10 \%$; in this case, oil prices could 
increase by up to $10 \%$, which could cause that the absolute rent obtained to be taken by the State as a producer only from the consumers [42]).

In the second case is found differential rent, as well as the conjectural rent, a form of absolute rent, which is temporary and affects the level of various resources. When prices fall, mines with marginal revenues suffer losses, and traders exploiting mineral deposits with low content of useful elements acquire their differential rent and gain higher profits. These phenomena affect the raw materials and energy prices, which are thus subject to large fluctuations [33].

In fact, both differential and absolute rent is acquired by two categories of businesses: owners and those who exploit the deposit. If the State, as owner of a certain area, has been prospecting, exploiting and evaluating this area, and hence of the size of differential rents they can get, it may assume an auction for that exploitation deposit. If auction generates competition, the State may acquire fully differential rent.

In fact, the state owner of marginal deposits will not get a lease without his income to cover a minimum of operation exploration and evaluation expenses, so to ensure the ability to reconstitute, at least theoretically, a part of his efforts to attract deposits in the economic circuit, plus a large part of the absolute rent [1]. When the State takes on the exploitation of the deposit, including specific services, it fully endorses both, the absolute and differential rent, assuming, however, geological research and risks [2].

Consequences of sharing rents differ from one country to another, from one pool to another. In general, economic operators are not interested in the production cost of a field in itself, but what they gain by selling mining products and fossil fuel after tax debt payment. Thus, if producing countries have deposits with the best geological and mining conditions they will get different forms of rent, operation being made either by private companies or by public companies. If the governments of those countries are willing to capitalize the capital invested, will focus on areas with low tax, even though production costs are high and risks of exploiting such deposits are high.

Convincing example is the U.S. many wells drillings in the Middle East for the exploitation of oil reserves with low production costs but high risk. In this area the State retains for itself most part of the rent, because it assumes the risk of geological research whose intensity depends on its long-term development strategies and policies. In these circumstances it is assessed that the division of rent by geographical area widely explains how to exploit the reserves of mineral resources which in turn will influence future supply structure.

Thus, if producing states retain much of the rent without being reinvested in exploration, so without the research to cover infrastructure costs and risks incurred by land companies specializing in geological research, mining can not be self-financing. Without a capital infusion from outside the industry or government authorities, therefore of outside risk assumed by them, exploration activity will be insufficient funded from within the industry under the conditions of lack of capital, and the volume of proven reserves will diminish gradually leading to an increased scarcity of raw materials and energy, and thus, to the occurrence and/or increased economic imbalances.

For eliminating such imbalances, countries that have reserves of mineral resources practice a price called price for exploitation right that theoretically is equal to the present value of future revenues that are expected to be given to investors, so the present value of rent. But value of these rents is impossible to predict accurately, the actual cost of operating reflecting in reality the economic players' forecasts regarding price developments of minerals extracted, the 
fiscal policy developments and all the factors that can influence the size of future rent.

Hence, differential rents will always exist, but their way of sharing and ownership are influenced by microeconomic logic of political and geopolitical factors, as by the level of competition between manufacturing industries and landowners with mineral deposits. Geographically, rent sharing is influenced by industrial players, particularly by their exploration targets, so by the change in a given timeframe of the offer, which in turn depends on production of marginal mine, on their importance and place of location.

The economic and mining literature considers that in the price structure of raw materials and energy are found both forms of rent, especially when considering the discounted price structure. In fact, when it comes to organizing a system of economic management of natural resources, especially non-renewable, we rely on discounted pricing theory.

* If given a geological reserve with one mineral resource, the sum of the quantities extracted over a period of time "T" must satisfy the relationship:

$$
\sum_{t=1}^{T} q_{t} \leq Q
$$

At the same time, be prices $\left(p_{1}, p_{2}, \ldots . p_{n}\right)$ associated with a program of rational management of mineral resources in question, $\left(q_{1}^{+}, q_{2}^{+}, \ldots . q_{T}^{+}\right)$, where the price

$\mathrm{p}_{\mathrm{t}}$ and quantities $\mathrm{q}_{\mathrm{t}}^{+}$are positive numbers. Assuming the cost of extraction is equal to 0 , discounted total net income for an extraction program $\left(q_{1}, q_{2}, \ldots q_{n}\right)$ is then:

$$
V_{a}=\sum_{t=1}^{T} p_{t} q_{t}
$$

And will reach the maximum defined by equation (1) in points $\left(q_{1}^{+}, q_{2}^{+}, \ldots q_{n}^{+}\right)$.
In this case, there must be a constant $\lambda>0$ that we call the absolute mining rent, for which:

$$
\begin{array}{lc}
\mathrm{P}_{\mathrm{t}}=\lambda & \text { if } \mathrm{q}_{\mathrm{t}}^{+}>0 \text { and } \mathrm{P}_{\mathrm{t}}>0 \text { if } \\
\mathrm{q}_{\mathrm{t}}^{+}=0 & \text { (2) }
\end{array}
$$

Considering that the interest rate "p" is constant, the resource price will be $\pi_{t}$, while respecting the condition (2) constant will be determined according to the relationship:

$$
\frac{\pi_{t}}{(1+p)^{t-1}}=\lambda \text { for all } \mathrm{q}_{\mathrm{t}}^{+}=0 \text { (3) }
$$

And resource price according to the relationship:

$$
\pi_{t}=\lambda(1+p)^{t-1} \text { for all } q_{t}^{+}=0
$$

Price $\pi_{\mathrm{t}}$ should thus increase exponentially with an average rate equal to the interest rate because the cost of extraction of natural resources can not be null, so the operation of a field can not be free of charge.

* In the case of " $n$ " different fields of mineral resources (when $\mathrm{i}=1,2, \ldots, \mathrm{n}$ ) existing in quantities $Q_{n}$, at the cost of extraction and preparation of each mining that equals $\mathrm{a}_{\mathrm{i}}$, the flow fields are attracted to production to the production costs as follows: $\mathrm{a}_{1}<\mathrm{a}_{2}<\ldots \ldots \mathrm{a}_{\mathrm{n}}$. In this case, the operating restrictions will be:

$$
\sum_{t=1}^{T} q_{i t} \leq Q_{i} \quad \text { for } \mathrm{i}=1,2, \ldots, \mathrm{n}
$$

Be $q_{\text {it }}$ a program of rational management of mineral resources where prices $\left(p_{1}, p_{2}, \ldots, p_{T}\right)$ are positive real numbers, and then discounted total net income for an extraction program $\mathrm{q}_{\text {it }}$ will be: 
$V_{a}=\sum_{i=1}^{n} \sum_{t=1}^{T}\left(p_{i}-\beta a_{i}\right) q_{i t}$

Where " $\beta$ " is the discounting factor for prices at a time horizon " $t$ ".

In this case, the interest rate is constant and equal to:

$$
\frac{1}{(1+p)^{t-1}}
$$

and to maximize the relationship (5) actually means maximizing profits of each trader operating a certain deposit. It follows that for each deposit of mineral resources there is a number $\lambda_{\mathrm{t}}>0$ so that:

$$
\pi_{t}-\beta_{t} a_{t}=l_{i} \text { if } \mathrm{q}_{\text {it }}^{+}>0
$$

And

$$
\pi_{t}-\beta_{t} \leq l_{i} \text { if } \mathrm{q}_{\text {it }}^{+}=0
$$

If the interest rate (6) is constant, the price $\pi_{\mathrm{t}}$ will be determined according to the relationship:

$$
\pi_{t}=a_{i}+\lambda_{i}(1+p)^{t-1}
$$

For all times when $\mathrm{q}_{\text {it }}^{+}>0$.

We can consider, in this case, that for all mineral deposits "i", $\lambda_{\mathrm{i}}$ can be interpreted as absolute rent, and if $\mathrm{i}<\mathrm{j}$ (so $\mathrm{a}_{\mathrm{i}}<\mathrm{a}_{\mathrm{j}}$ ), difference $\lambda_{\mathrm{i}}-\lambda_{\mathrm{j}}$ constitutes the differential rent which may be obtained by exploiting deposit "i" against deposit "j".

Comparing the approach of the land rent and the mining rent can be pointed out the similarities and differences between how they are composed. In this respect, we have found out that highlighting both the problems of composing and acquiring mineral rent, and the procedures and forms in which the rent is reflected in the price of mining products and energy resources are basic premises to emerge specific methodological elements of economic management of mineral resources. As our researches revealed, contractual duties, further discussed, represent one of these elements.

\section{Contractual Duties}

As the present is known with certainty, contract tax policy should be decided before the existence or the size of the resource. Formally, contracts for exploration and extraction are, of course, signed before you start exploring, and risk charge is often defined by these contracts. If you would not do so, the risk would be worse because there is a possibility in terms of taxation to be arbitrarily changed after the discovery of the resource [38].

Tolling system contract, according to which a foreign firm agrees to operate an area with natural resources, is a "sharing-scheme for total revenue" of the project. At the start of operation, they consist of the opportunity cost of capital which the company will invest, revenues for the risks assumed, and rent recognition that will appear in this area.

Hence, tolling system contract defines the default mode where each level of income (positive or negative) that is acquired after exploration and production will be split between companies and government. Different schemes have different effects in terms of firm choice about the path of development and production for a reserve that is discovered.

This means that they will provide a different structure of incentives for the contracting company. Instead, it affects both the total revenue from the project, and the annuities/rents that can be derived from it. In economic terms, the problem is to select and/or design an efficient system of charging for obtaining contractual element in terms of resource rent uncertainty on the resource. 
In the process of exploring natural resources in a given perimeter, the possibility of changing the value that the firm and a government agree on the perimeter before and after its exploration is inherent. This source gives the possibility for one party to want to amend (explicitly or implicitly) the contractual terms after the exploration ends, where the penalties for such a situation are small. Expropriation should be included in this risk.

The issue of Sovereign (Property) Risk (Government changing contractual terms) is due to the particular relevance for less developed countries, and is very important as long as it affects both the risk perceived by foreign firms, and the contractual conditions that they are willing to grant.

The present analysis is intended to present and evaluate a variety of different systems for contractual taxation that might be used in developing countries. The idea is to determine this variety in different economic and geological conditions; of particular interest are the geological conditions that allow a low probability to discover new resources. The hypothesis was that, although current rates that are fixed in any given schema are designed to be sensitive to basic conditions, some regularity should appear in effectiveness of the schemes themselves.

Further analysis also explores how the contractual forms of taxation may reduce "the risk of property" and therefore increases profits (ex-ante) of both parties. An evaluation of various rules of tolling contract extension-system considered above, meets the derived analytic criteria of property risk reduction. Although our simulations were based on oil resources, there are general problems of charge assessments on the foreign companies involved in exploration and production of other exhaustible resources too.

\section{Different Systems for Contractual Taxation}

Studying different types of contractual duties led to highlighting the following contractual taxation systems that may be successfully applied in developing countries:

1. Property Tax (Royalties Tax) seems to be the most inefficient rent system of extraction of natural resources rents. Such a system was sometimes justified on grounds where developing country governments have obtained a discount rate higher than the company (revenues that governments wanted to appear soon). We have found that, under these conditions, the property system is deteriorating faster than the others.

2. A simple Income Tax, commonly used for other production activities, including extracting mineral resources countries, although is not the best system is a reasonably effective system. For this purpose, the tax rate is a rate that should be fixed at a convenient value of geological prospecting and economic conditions.

3. A Production Share System, simplified to a single level instead of sharing multiple levels (as usual in these systems), have marginal results worse than the simple income tax system. With multiple levels, the efficiency of these systems falls dramatically, becoming more stupid than one level system.

4. A Resource Rent Tax System is considered as the most efficient system. Greater attention should be given not to fix the highest Accumulation Rates applicable in relation to the discount rate. The most effective accumulation rate depends also on income tax of the host government, and is directly linked to it. For example, we found out that with no income tax, but with an accumulation rate of $10 \%$ in connection with a discount rate of $6 \%$, rent resource tax system becomes the most inefficient system. An income tax rate of $15-30 \%$ of the host government is often effective.

On the other hand, it is interesting that the rent resource tax system is regarded as the most progressive system. In fact, other 
schemes mentioned above are all regressive type schema, meaning that the correlation between the host government share and the present value of the project is negative.

5. Tax on resource rent with multiple levels (Resource Rent Taxation), which is explicitly designed to increase the progressivity of this system, here does not have such an effect in the absence of an income tax. Setting a single, adequate resource rent tax is able to respond to level progressivity in a multi-level system. In the presence of domestic taxes on income, multiple levels can be used to improve progressivity.

We have found out that change in accumulation rates on rent resource tax system shows a relationship between efficiency and progressivity. If efficiency is negative then positive progressivity may be related to the accumulation rate. The relationship between them is characterized by two well-defined segments.

In the initial segment, because the rate of aggregation has values over the discount rate of the company, progressivity increases rapidly with only small loss of efficiency. In the second segment, using a critical aggregation rate, the position is reversed, resulting in a rapid decrease in efficiency and small gains in efficiency.

6. Separate theoretical analysis suggest that Sovereign Risk Nationalization can be mitigated by a system where the host government share increases with the size of proven reserves amount for the perimeters of very high values. So, progressive tax system on resource rent being the only one having these characteristics is not sufficient to reduce the risk of nationalization by a significant factor.

7. As multilevel systems of production sharing, Variable Profit Share and Variable Royalty Systems, which continuously have variable tax levels, seems to be very inefficient. Their effectiveness is often worse than the system with two levels of production sharing. At this point, a much clearer conclusion is not possible because the degree of progression rate is very important. These systems are also regressive.

With the exception of resource rent tax system with accumulation rates greater than the firm's discount rate, efficiency and progressivity are usually in positive relationship. Therefore, it is sufficient to consider only their efficiency properties.

In practice, a version of income tax applied to British Petroleum allows firms not to pay any tax on originally specified volume of production, thus being less efficient than property tax [29]. When the allowed volume is reduced to zero, the system improves considerably. As it is now built, one might say that this system will extract competitive rents only when the probability of reserves discovery is very small. For a better job of geological prospecting, all the additional revenue obtained will go to companies.

\section{Types of Inefficiency of Resources Management}

TEV and SOC are related. We noted that if a resource is used rationally, the external cost of resource use is likely to be lower than if the resource should be used irrationally. If the resource is used irrationally, the stock will decline. As long as the threat exists, in general, over non-commercial uses - such as recreation, future use values (optional value) and non-use values (existential value) - TEV loss will occur. This means that TEV enters in SOC's formula as "observer" of external cost.

Another source of inefficiency in resource use may occur in the government market intervention [10]. Thus, subsidies may exist, accelerating non-optimal depletion of exhaustible resource or irrational use of renewable resources. At the inefficiency that may occur due to neglecting external 
environmental costs in a free market, we add these inefficiencies inspired by the government, even if the interaction of the two sources of inefficiency is not always cumulative.

Hence, the previous section can be synthesized in non-technical terms, as follows:

1) External costs and future user costs occur even when a resource is used rational or irrational, but they will be much higher in the second case.

2) Different property rights regimes (e.g., private property over common property) can be compared in terms of relative efficiency of use.

3) As long as a renewable resource is used irrationally, its stock will tend to diminish and perhaps it will cause losses occurrence in TEV.

4) Due to the large potential of market system in neglecting the preservation value (TEV of resource preservation) there is a clear tilt in favor of preserving ecologically valuable land for development purposes.

5) Government intervention in the market of natural resources often has the effect to increase the resources inefficiencies identified on private markets.

6) Redefining property rights provides clearly a more significant potential for minimizing conflicts costs for resource multi-use. Significantly, attempts may occur to adopt this solution that requires addressing the objective function towards strictly limited bureaucratic goals. This avoids the extending of fuzzy phenomenon that appears in the standard neoclassical definition of the objective function, but at the cost of possible significant potential for ignoring value components.
Assessing inefficiencies. It is therefore important to identify sources of inefficiency and, as far as possible, to see which are the most important. This action requires a methodology for evaluating the degree of inefficiency. As long as externalities are concerned, we may follow the monetary evaluation process as much as possible.

In the term "government inefficiency", OECD studies suggest that water pricing policy often fails to recover development costs and to reflect environmental costs of water supply, which is also true for forestry. This suggests a review of various incentive mechanisms for water and forest management in OECD countries.

The special case: Market and government failure. Despite the distinction made by some authors between market and government failure [23], it is advisable to use here this situation in organizational purposes only. The exact mode in which simultaneous existence of non-market accounts for externalities, on the one hand, and government intervention affecting resource use, on the other hand, can not be known with certainty.

This is because resource depletion may be less in an imperfect market, as with "monopolies", which means that we expect monopolist owners to restrict up to what level a resource is extracted or harvested. This situation occurs because monopolist owners can get profits from such activities.

In this respect, we must emphasize that the use by the host government of a credit system in place of taxing income deductions from external sources system makes no distinction between the effectiveness of different systems.

Our researches demonstrate that the largest possible part of the resource rent is taken by the host government in the case of credit system; under these circumstances we recommend that the host government should use an effective rate of income tax equal to 
the firm rate in order to obtain the maximum amount of rent.

In the light of these facts, we also recommend that this kind of system should be combined with the resource rent taxation, with a reasonably high accumulation rate to maintain efficiency.

For example, with an effective taxation rate of domestic income by $45 \%$, an even effective income tax may also be combined with a resource rent tax system on an accumulation rate of less than 2.5 times the discount rate of the company.

\section{Conclusions}

In conclusion, differential rents will always exist, but their way of sharing and ownership are influenced by microeconomic logic of political and geopolitical factors, as by the level of competition between manufacturing industries and landowners with mineral deposits.

Geographically, rent sharing is influenced by industrial players, particularly by their exploration targets; in other words, rent sharing is influenced by the change in a given timeframe of the offer, which in turn depends both on production of marginal mine, and on their importance and place of location.

The economic and mining literature considers that in the price structure of raw materials and energy are found both forms of rent, especially when considering the discounted price structure [22]. We say that, in fact, when it comes to organizing a system of economic management of natural resources, especially non-renewable, we have to rely on discounted pricing theory [21].

At the same time, economic literature has often argued with the idea of resource reserves depletion, due to the extent of economic and demographic development. Hence, economic and population growth lead to increasing consumption of natural resources. Given that natural resources are limited, their stock volume must be known to determine the duration of their use until complete exhaustion, for non-renewable resources, or their decrease level of stocks per capita, beyond subsistence level assurance, for renewable resources.

Is noticeable that both methodological elements and modalities of to present these elements depend on the type of mineral resources also. For example, pricing mechanisms for delivery of mining products are different from those of energy resources. Thus, speaking of energy resources, the energetic coal pricing arrangements are different from those of oil or gas pricing. Going to analyze in more detail, there are big differences between energetic hard-coal pricing compared to those of lignite pricing.

Moreover, to broaden the analysis, a special problem is also the composing and acquiring of rent in case of forest resources (like land rent), as well as how this rent is reflected in the forest products price. Similar to mining industry, in fact, the existence of rent in forestry is given by the quality of forest resources and the geographical location of forests, and is influenced by the size of demand for timber.

In conclusion, as related to natural resources management seen through mining rent theory, we can really distinguish three potential sources of inefficiency in resource use, not acting in the same direction. These are:

1) Externalities: over-failure costs neglect of resource use. This allows us to strive to current rates too high for use of resources.

2) Monopoly: restrictions on production due to profit. This makes the current rates too low for use of resources.

3) Government intervention: the use of subsidies and tax laws. This leads to excessive current rates of resources use only if they occur to correct the type (1) inefficiencies. 
With this analysis we have made a perfect analogy to pollution situation, as we know, for example, that a pollutant load that takes into account only externalities can not produce optimal results if significant imperfections exist on pollutants producing market [7].

\section{References}

Barnett, H. J. (1979). 'Scarcity and Growth Revisited,' in Scarcity and Growth Reconsidered (editor: V. K. Smith), Johns Hopkins University Press, Baltimore, MD.

Barnett, H. J. \& Morse, C. (1963). "Scarcity and Growth: The Economics of Natural Resource Availability," Johns Hopkins University Press, Baltimore, MD.

Bator, F. M. (1958). "The Anatomy of Market Failure," in Quarterly Journal of Economics, 72.

Baumol, W. \& Oates, W. (1971). 'The Use of Standards and Prices for the Protection of the Environment,' Swedish Journal of Economics, 73.

Beenstock, M. (1983). 'Pull the Plug on OPEC,' in The Guardian, 30 November.

Buchanan, J. M. (1969). "External Diseconomies, Corrective Taxes and Market Structure," in American Economic Review nr.3.

Bulearca, M., Badileanu, M., Popescu, C. \& Muscalu, M. S. (2010/1). "Models for Determining Taxes on Pollution - A Major Goal for Environmental Purposes," Proceedings of the International Conference of the Institute for Environment, engineering Economics and Applied Mathematics (IEEAM) "Development, Energy, Environment, Economics (DEEE)", Tenerife, Spain, November 29 - December 2, 2010.

Bulearca, M., Serban, E. C., Badileanu, M. \& Muscalu, M. S. (2010/2). 'Rents Theory And Modelling Mining Rents,' Proceedings of the
International Conference of the Academy of Economic Studies of Bucharest, in Supplement of "Quality-access to success" Journal, Year 11, no. 118, 2010, published by the Romanian Society for Quality Assurance, Cybernetics MC Publishing House, Bucharest, November 11, 2010.

Coase, R. H. (1960). The Problem of Social Cost, in Journal of Law and Economics, no.3.

Dersochers, P. (2008). "Did the Invisible Hand Need a Regulatory Glove to Develop a Green Thumb?", Environ Resource Econ, 41:519-539.

Douthwaite, R. (1992). 'The Growth Illusion, How Economic Growth Has Enriched the Few, Impoverished the Many and Endangered the Planet,' Lilliput Press, Dublin.

FarrelL, J. (1987). "Information and the Coase Theorem," in Journal of Economic Perspectives.

Friedman, M. (1953). Essays in Positive Economics, University of Chicago Press.

Gray, L. C. (1916). 'Rent Under the Assumption of Exhaustibility,' Quarterly journal of Economics nr. 28.

Hartwick, J. M. \& Olewiler, N. D. (1986). The Economics of Natural Resource Use, Harper \& Row, New York.

Heckscher, E. (1919). 'The Effect of Foreign Trade on the Distribution of Income,' Ekemisk Tidskrift.

Hillman, A. L. \& Bullard, C. W. (1978). "Energy, The Heckscher-Ohlin-Theorem and US International Trade," in The American Economic Review.

Hotelling, H. (1931). "The Economics of Exhaustible Resources," in Journal of Political Economy 39, London.

Howe, C. W. (1979). "Natural Resources Economics, Issues, Analysis and Policy," Wiley, New York. 
Iancu, A. (1983). "International Economic Exchanges," Scientific and Encyclopedic Publishing House, Bucharest.

Kula, E.. (1989). 'The Modified Discount Method - Comment on Comments,' in Project Appraisal nr.3.

Kula, E. (1994). 'Economies of Natural Resources, the Environment and Policies, Second Edition,' Chapman and Hall, London.

McKelvey, V. E. (1972). "Mineral Resource Estimates and Public Policy," in American Scientist, 60.

Meade, J. E. (1981), 'Economic Policy and the Threat of Doom,' in A. Butlin (editor) Economics and Resources Policy, Longman, London.

OPEC (1982). 'A Comparative Statistical Analysis,' Carl Verberrenter Ges, Vienna.

OPEC (1988). 'Facts and Figures,' the Secretariat, Vienna.

Pearce, D. W. (1981). The Dictionary of Modern Economics, MacMillan Press, London.

Pearce, D. W. (1983). 'Cost-benefit Analysis, Second Edition,' MacMillan, London.

Pearce, D. W. \& Turner, R. K. (1990). Economics of Natural Resources and the Environment, Harvester Wheatsheaf, London.

Rajaraman, I. (1976). 'Non-Renewable Resources: A Review of Long Term Projects,' in Futures, 8.

Ricardo, D. (1817). 'Principles of Political Economy and Taxation,' republished by Pelican Books, London, 1971.

Samuelson, P. A. \& Nordhaus, W. D. (1992). 'Economics, 14-th Edition,' McGraw Hill Book Co., New York.
Slade, M. E. (1982). "Trends in Natural Resource Commodity Prices: An Analysis of the Time Domain," in Journal of Environmental Economics and Management nr.9.

Smith, L. G. (1993). "Impact Assessment and Sustainable Resource Management," Longman Scientific and Technical, Harlow, England.

Smith, V. K. (1979). 'Scarcity and Growth Reconsidered,' John Hopkins University Press, Baltimore, MD.

Tahoven, O. \& Salo, S. (2001). "Economic Growth and Transition between Renewable and Non-Renewable Energy Resources," Eur Econ Rev, 45:1379 1398.

Tietenberg, T. (1992). 'Environmental and Natural Resources Economics,' Third Edition, Harper-Collins, New York.

Veron, R. (1970). The Technology Factor in International Trade, National Bureau of Economic Research, New York.

Virmani, A. (1985). Tax and Contractual Arrangements for the Exploitation of Natural Resources, The World Bank, Washington D.C., U.S.A.

Wannacott, P. \& Wannacott, R. (1986). 'Economics,' Third Edition, McGraw Hill Co., New York.

Withagen, C. (1994). "Pollution and Exhaustibility of Fossil Fuels," Resources Energy Econ, 16:235-242.

Wunderlich, G. (1967). 'Taxing and Exploiting Oil: The Dakota Case,' in Extractive Resources and Taxation (editor: M. Gaffrey), University of Wisconsin Press, Madison, WI. 